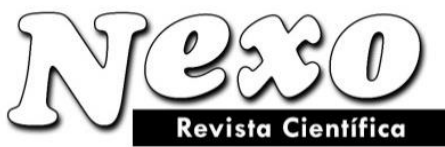

Vol. 34, No. 01, pp. 504-513/Marzo 2021

\title{
Logical model of mobile object control
}

\section{Modelo lógico de control de objetos móviles}

\author{
Stanislav A. Kudzh*, Victor Ya. Tsvetkov \\ MIREA - Russian Technological University. \\ *rektor@mirea.ru
}

(recibido/received: 08-December-2020; aceptado/accepted: 24-February-2021)

\begin{abstract}
This paper describes a logical model applied as a soft control tool to mobile objects. The model of the logical spatial situation without uncertainty, i.e., according to the law of excluded middle, is considered as the basis. Nonetheless, the motion rules are derived using an approach applied in constructible mathematics and logic. The approach consists in the finitude of variants of control and analyzing all potential traffic scenarios. The constructible object considered in this paper is the situation's logical model. The constructible approach consists in considering the model of a typical railway station by the example of which the traffic is analyzed. The situation's logical model is implemented as a condition for potential traffic. This model is described using mathematical logic with the help of logical variables and rules. The control system in this case makes use of permissible versions of logical designs. The control relies on the feasibility of traffic. The system of control rules is developed on the basis of the logical situation's model and formed without uncertainty. The article provides an analysis of complementary kinds of traffic.
\end{abstract}

Keywords: Information situation; Logical model; Soft control; Topological model.

\section{RESUMEN}

Aquí se describe el modelo lógico usado como un medio de control moderado de objetos móviles. Se considera como base el modelo de la situación lógica espacial sin incertidumbre, o sea, según el principio del tercero excluido. A pesar de ello, se derivan las reglas de tráfico a traves de un enfoque aplicado en matemáticas estructurales y lógica. El enfoque consiste en la finitud de variantes de control y analizar todos los escenarios potenciales del tráfico. El objeto diseñable considerado aquí es el modelo lógico de la situación. El enfoque estructural consiste en considerar el modelo de una estación ferrocarril típica usado como un ejemplo para analizar el tráfico. Se usa el modelo lógico de la situación como una condición para tráfico potencial. Se describe este modelo a través de lógica matemática con la ayuda de variables y reglas lógicas. En este caso el sistema de control hace uso de versiones permitidas de diseños lógicos. Se basa el control en la viabilidad del tráfico. Se usa el modelo de la situación lógica espacial sin incertidumbre como base para desarrollar el sistema de reglas de control. Aquí también se analizan los tipos del tráfico complementarios.

Palabras claves: Situación de información; Modelo lógico; Control moderado; Modelo topológico. 


\section{INTRODUCTION}

The features of mobile object control (Tsvetkov, 2012) differ it from stationary object control. Mobile object control is divided in soft and rigid (Chtioui, 2011) and makes it necessary to take account of geographical factors (Ishikawa, Tsuchiya \& Yamamoto, 2017) and the multitude of mobile objects (Miyahira \& Yamamoto, 2016). Rigid or prescriptive control is based on elaborating controlling actions applied to a controlled object. Soft control is based on creating conditions or situations for a controlled object (Abdelrahim \& Razdan, 2014). A case of rigid control is the one exercised from a vehicle traffic operations control centre. A case of soft control is the traffic management by light signalling. The soft control on railway lines is exercised using signal-based traffic management by blocks. A block is a section between two traffic signals. The green light provides traffic authorization and allows switching from one block to another. The red light imposes traffic restrictions. There is also a third kind of control called subsidiary (Tsvetkov, 2012). In this kind of control specific issues in a strategic task are resolved on site or as the case may be. Essentially, this control can be treated as a kind of structurally variable soft control (Adamy \& Flemming, 2014). For example, subsidiary control is used on digital railways (Nemtanu \& Marinov, 2017). Soft and subsidiary control make use of topological models as the base for organizing control conditions. Logical models can be used in control only with the help of discrete models, spatial information and geodata (Savinykh \& Tsvetkov, 2014). Soft control makes it necessary to use a spatial information situation. Conventional discrete object control makes use of differential equations. Solutions for differential equations are continuous functions and, actually, can be unlimited in number. The struggle against infinite solutions and sets in the early twentieth century gave rise to constructivism, intuitionism, and constructible mathematics. One of the major principles of this trend is the utilization of finite objects and denumerable sets. The modeling and control exercised using this approach relied on choosing finite and feasible models. A finite set of models or situations was used to derive a combinatory, discrete or logical solution for a problem. Logical control depends on the chosen kind of logic - binary or ternary. Binary logical is based on the law of excluded middle recorded as $\mathrm{A} \vee \neg \mathrm{A}=1$, where $\mathrm{A}$ is a certain event and $\neg \mathrm{A}$ is its inversion. The existence of uncertainty requires applying ternary logic. Uncertainty can be excluded using a finite number of variants for a particular situation. Logic is the base for forming a logical situation (Shchennikov, 2018) used as the base for control.

Constructible mathematics makes possible the existence of constructible objects. This opinion differs from the notion of existence accepted in set-theoretical mathematics. The law of excluded middle is not a universal principle in constructivism. Constructivism dates back to the works of Dutch scientist L. E. J. Brouwer $(1908,2007)$ who supposed that the root of non-constructive theorems of existence was found in classical logic. Note that classical logic has been created not so much for build-ups as for refutations.

The main task in constructible logic is to find potential build-ups. The orientation at the possibility of essential build-up has allowed the constructivists to develop a number of techniques way closer to reality than those intended for direct applicability. A case of this constructible system is notice board (Rozenberg, 2016). In this case the constructible approach is implemented by making up rules of potential traffic as applied to a preset situation.

Traffic control makes it expedient to use information situation models. (Tsvetkov, 2012). An information model is a model with a set of connected objects; it models a group of objects, not one single object.

A spatial information situation (Pavlov, 2016) is a variety of information situation. If it includes linear objects, it can be described using a topological model. A merit of this situation is that it allows combining situational, topological, and logical analysis.

Railway transport is a well-functioning system with rare uncertainties. The absence of uncertainty allows using classical logic in analyzing traffic and situations. 
This work proposes an integral model combining the principles of constructible mathematics (Martin-Löf, 1982), spatial situational analysis (Pietrzak et al., 2008), and logical analysis, for example, European Train Control System (ETCS) (Platzer \& Quesel, 2008). The proposed model is a step towards the continued modeling of situations in distributed systems.

There are two approaches to control operations, rigid control and soft control. The proposed logical model refers is a case of soft control, relies on the conditions in a managerial situation, and forms vehicle traffic conditions, proceeding from the stated conditions.

It is necessary to note that soft control differs from soft computations: these notions are essentially different. Soft computations are based on the fuzzy set theory. Soft control makes use of a clear situational model using the combinatory approach with a finite number of variants.

\section{MATERIALS AND METHODS}

The materials used include the accumulated experience in mobile object control. The method used as the main one is the idea of applying non-obvious knowledge (Sigov \& Tsvetkov, 2015) for describing the situation with possible motion variants of a mobile object. Logical models and mathematical logic are used for formalizing the situation and motion variants.

\section{RESULTS AND DISCUSSION}

\subsection{Information Situation and Spatial Situation}

Any kind of control consists in developing or choosing managerial solutions out of a certain set of permissible solutions. Each solution includes controlling actions. All cases of control make it necessary to examine a managerial situation (Mayer, Winter \& Mohr, 2012). Information modeling methods allow converting it to an information situation model.

In terms of developing management schools (Rozenberg, 2016) situational control is tied to the managerial trend called "control in unforeseen circumstances". Situational control makes use of the information situation model that is the base for subsidiary and complementary control (Alvarado, 1995). These notions are also rarely used in traffic control.

Situational control is divided in analytical and stereotypical. The decision making in situational stereotypical control relies on analytical comparison. In this case the current situation and the parameters of an object involved in this situation are evaluated. This evaluation is used to compare the current managerial situation with a set of similar situations the managerial solutions of which are known. Then the most similar situation is picked from this set and the solution of this situation is used to resolve the current situation.

This method will not work in unforeseen circumstances or in situations with a new combination of parameters. In this case, the analytical approach is used consisting in analyzing the situation and elaborating a specific solution exactly for this managerial situation. In this case, several models have to be formed that allow adequately indicating the state of the object interacting with the environment.

The information situation model is not singular and has several versions conditioned by the consideration of the situation and the phase of the problem being solved. 
In the initial phase of solution search the information situation appears as a condition or as an information situation condition. The general conditions for solving a managerial problem are a sum of initial parameters. The information model as a condition supplements the initial parameters with new relationships and links among the condition's parameters, which improves awareness and reduces information uncertainty (Tsvetkov, 2015).

The information situation as a condition is a connected sum of parameters otherwise separated and loosely related outside this model.

In the next phase of solution implementation the information situation has a different quality and a different type. The solution process involves using the information situation model as a process model. This information situation model has the corresponding algorithm or model of computational streams. In this phase the information model acts as a process model.

In the final computational or control phase the information model plays another role. After the controlling solution is received or the control cycle completed, the information situation model appears as the result.

This is the information model of the result's description. Unlike the usual set of parameters as a result, the information situation discloses the relationships and links among other results and allows accumulating and generalizing managerial experience. In this phase the information situation takes the form of new knowledge and accumulated experience.

Information situation is a multiaspect notion. The information situation model viewed as an experience drives up the quality of transport services. Information situation as a model of knowledge allows predicting the development of the transport industry and transport infrastructure. The spatial information situation allows applying the techniques from information science and GIScience to the field of transport control. It is necessary to define the information situation as an information model.

The information situation (IS) in transport control is an integral process and spatial model with interconnected key parameters. It allows solving a control task or going through a control phase with better awareness.

The information situation as related to the controlled object is divided in two kinds: it may include a controlled object and be treated as a complex system or it may be treated without a controlled object, as a subset of the environment or as the semantic vicinity of a controlled object. The information situation has a purpose; in this respect, it is divided in "situation-condition", "situation-process", and "situation-result". The spatial information situation always covers more space in comparison with the controlled object's space.

In terms of dynamics the information situation is more dynamic and variable in comparison with the controlled object and can describe not one but a group of objects. The additional information situation models that can be distinguished are the information situation of object interaction, the information situation around a mobile object, and the information situation of states of a mobile object.

The information situation can be treated as a complex system, which makes it possible to apply systems analysis techniques to investigating this situation. If to use the system description proposed in paper (Martin-Löf, 1982), the spatial information situation (SIS) model can be recorded as

$$
\text { SIS =F2(MOi, Ps, TM, Co, Ce, Ros, IntS), }
$$

where MOi is the model of objects in given situation $i=1 \ldots$.; Ps are the parameters of the situation, Co are the interobject connections, Ce are the connections between the controlled object and the environment, 
Ros are the interobject relationships, IntS are the information interactions among the objects, TM is the topological spatial model.

The mandatory availability of a topological model is the essential distinct feature of the spatial information situation compared with the parametric information situation model. In terms of quantity expression (1) includes much more factors than the object model's description.

In the current context the information situation has such a major characteristic as complexity. For the model of a complex spatial information situation see Fig. 1. The model contains several lines shown as arc sections and arrow nodes. This topological model contains no mobile objects. This situation can be called a static information situation; however, it does set the conditions for the object's motion.

\subsection{Logical Information Situation}

Information situations include technical, temporal, logical, and resource parameters and are divided in descriptive and prescriptive (Tsvetkov, 2015). The descriptive information situation represents a real situation. The prescriptive information situation is a system of rules that prescribes certain actions in a specific situation or restricts the processes in such.

The prescriptive information situation is a control tool for intelligent or cyberphysical transport systems. It is based on a system of rules. The rules can be elaborated using classical or constructible logic. If the former is used, the prescriptive situation will be formed as a system of logical structures. This system relies on the spatial situation and traffic conditions. The logical information situation can be supplemented with the topological model.

The logical information situation can describe traffic conditions, motion process, and motion results. For the pattern of the logical information situation "conditions" see Fig. 1. This situation determines the conditions of potential motion variants only, i.e., uses the principles of constructible mathematics.

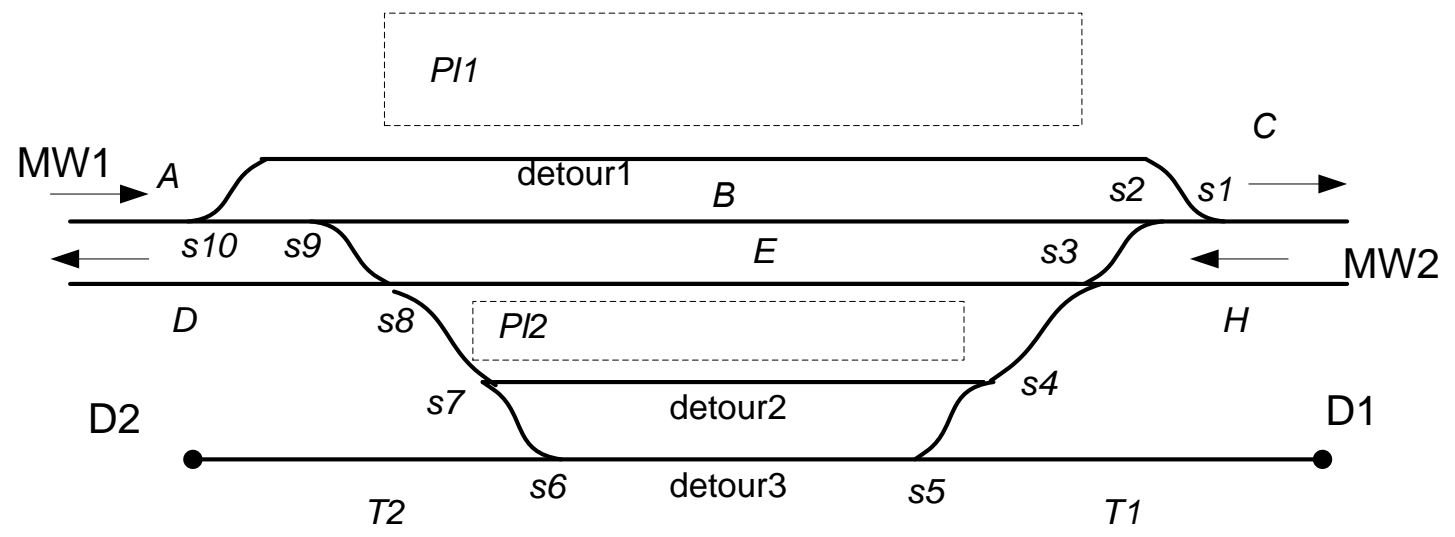

Figure 1. "Motion condition" information situation

Figure 1 shows two main ways (MW1, MW2) and three by-ways (detour 1, detour 2, detour 3). The nodes in the topological model correspond to railway points and are shown as symbols si $(\mathrm{i}=1 \ldots 10)$. The Figure also shows two spur tracks D1, D2. The main ways consist of sections MW1 (A, B,C) and MW2( H, E, D). Perrons 1 and 2 are indicated as P11 and P12.

The track sections are indicated with Latin capitals simultaneously used as logical variables. The logical variable equal to 1 (true) means that the train is currently located in this section. The logical values of the nodes (railway points) are 1 (direct traffic) and 0 (reverse traffic). 
The additional traffic parameters are:

general traffic control signal $\mathrm{m}=1$ (true) (traffic allowed), and $\mathrm{m}=0$ (traffic prohibited);

emergency stop signal ( $\mathrm{a}=1$ is emergency stop, and $\mathrm{a}=0$ is no emergency stop).

The prescriptive information situation is drawn using the logical functions and the layout in Fig. 1 as the condition.

The logical information situation in Fig. 1 is characterized by the following key parameters and their logical values:

- Logical variables showing that the train is found in a specific section: $\mathrm{A}=1, \mathrm{~B}=1, \mathrm{C}=1, \mathrm{D}=1, \mathrm{E}=1$, $\mathrm{H}=1, \mathrm{~F}=1$, Detour1=1, Detour2=1 mean that the train is found in a given track section. The alternative indicated with the negative or inversion sign as $\neg \mathrm{A}, \neg \mathrm{B}, \neg \mathrm{C}, \neg \mathrm{D}, \neg \mathrm{E}, \neg \mathrm{H}, \neg \mathrm{F}$, $\neg$ Detour $1, \neg$ Detour 2 means that there is no train in the given track section. The $(\neg)$ sign indicates that the logical variable is inverted;

- The si signals from automated point sensors are $s i=1$ (direct traffic) and $\neg$ si means si=0 (turn);

- The control signals are $\mathrm{k}=1$ (traffic allowed) and $\neg \mathrm{k}=0$ (no traffic);

- The emergency stop signals are al=1 (emergency stop) and $\neg \mathrm{al}=0$ (no stop);

- $\quad$ The signals from platform sensors are $\mathrm{P} 11=1, \mathrm{P} 12=1$ (platform free) and $\neg \mathrm{P} 11=\neg \mathrm{P} 12=0$ (platform busy);

- The signals from track section sensors correspond to the Latin capitals used for track sections and also have two meanings: $\mathrm{a}=\mathrm{b}=\mathrm{c}=\mathrm{B}=\mathrm{f}=\mathrm{h}=$ (etc.) $=1$ means "track section free", whereas $\neg \mathrm{a}=\neg \mathrm{b}=\neg \mathrm{c}=\neg \mathrm{d}$ (etc.) $=0$ means "track section busy";

- $\mathrm{h}$ signal means that all of the train doors closed $(\mathrm{h}=1)$;

- signals $h c=1, h d=1$ mean that all of the doors on platforms Pl1 and Pl2 are closed. This option is switched for high-speed trains passing by a platform without stopping.

Let us use the spatial information situation layout from Fig.1 to build a system of logical rules for potential traffic. The through traffic along main way MW1 (from left to right) from section A to C is

$$
\begin{gathered}
A \rightarrow \neg B \neg C \\
F l=(k \wedge \neg a l \wedge s 10 \wedge s 9) \wedge((k \neg b \wedge \neg a l) \wedge(k \neg c \wedge \neg a l \wedge s 2 \wedge s 1))
\end{gathered}
$$

The through traffic along main way MW2 (from right to left) from section H to D is

$$
\begin{gathered}
H \\
F 2=(k \wedge \neg a l \wedge s 3) \wedge(k \wedge \neg a l \neg e) \wedge(k \wedge \neg a l \neg c \wedge s 8))
\end{gathered}
$$

The traffic with a stop along main way MW1 (from left to right) from section A to Detour1 is

$$
\begin{aligned}
& A \rightarrow \neg \text { Detourl } \\
& F 3=(k \wedge \neg a l \wedge s 10) \wedge(\neg \text { detour })
\end{aligned}
$$

The traffic after the stop, from by-way Detour1 to main way MW1 (from left to right), from section Detour 1 to $\mathrm{C}$ is

$$
\begin{array}{r}
\text { Detour } \rightarrow \neg C \\
F 4=(h \wedge k \wedge \neg a l \neg s 10) \wedge((k \wedge \neg a l \neg c)(4)
\end{array}
$$


The traffic with a stop along main way MW2 (from right to left) from section H to Detour2 is

$$
\begin{aligned}
& H \rightarrow \neg \text { Detour2 } \\
& F 5=(k \wedge \neg a l \wedge \neg S 3 \wedge \neg S 4) \wedge(\neg \text { detour } 2)
\end{aligned}
$$

The traffic after the stop, from by-way Detour2 to main way MW2 (from right to left), from section Detour2 to $\mathrm{D}$ is

$$
\begin{array}{r}
\text { Detourl } \rightarrow \neg D \\
F 6=(h \wedge k \wedge \neg a l \neg s 8) \wedge((k \wedge \neg a l \neg d)
\end{array}
$$

The layout in Fig. 1 makes through traffic possible when the main way sections passing through by-ways are busy. The through traffic along main way MW1 (from left to right) from section A to C through byway Detour1 is

$$
\begin{gathered}
A \rightarrow \neg \text { Detour } \rightarrow C \\
F 7=(k \wedge \neg a l \wedge s 10 \wedge s 9) \wedge((k \neg \text { detour } 1 \wedge \neg a l \wedge h c) \wedge(k \neg c \wedge \neg a l \wedge s 2 \wedge s 1))
\end{gathered}
$$

The through traffic along main way MW2 (from right to left)bfrom section H to D through by-way Detour2 is

$$
\begin{gathered}
H \rightarrow \neg \text { Detour } 2 \neg D \\
F 8=(k \wedge \neg a l \wedge \neg s 3) \wedge(k \wedge \neg a l \neg \text { detour } 2 \wedge \neg s 4) \wedge(k \wedge \neg a l \neg c \wedge \neg s 8))
\end{gathered}
$$

The round parentheses in expressions (2-9) contain contextually connected parameters shown as conjunction blocks, which is allowed in mathematical logic. Complementary logical function equations can be composed using complementarity relationships. Complementary control means identically true conjunction functions, i. e.,

$$
\begin{gathered}
F 1 \wedge F 2=1 . \\
(F 3 \wedge F 4)(F 5 \wedge F 6)=1 . \\
F 7 \wedge F 8=1 .
\end{gathered}
$$

Logical complementarity means that the respective expressions make possible joint traffic along dedicated routes and do not affect each other. This makes synchronous traffic possible. Expression (10) indicates the possibility of independent traffic with stops along the routes

$$
A \rightarrow \neg B \neg C \text { и } H \rightarrow \neg E \neg D
$$

Expression (11) indicates the possibility of independent traffic with stops along the routes

$$
A \rightarrow \neg \text { Detour } 1 \neg C \text { и } H \rightarrow \neg \text { Detour } 2 \neg D
$$

Expression (12) indicates the possibility of independent traffic without stops along the routes

$$
A \rightarrow \neg \text { Detour } 1 \neg C \text { и } H \rightarrow \neg \text { Detour } 2 \neg D
$$

The proposed system of traffic control rules describes three kinds of traffic along both ways. The model can be developed by supplementing it with conditions for sorting using backup tracks or for moving the objects to spur tracks. This paper provides the essential problem statement and the techniques of formulating traffic rules. 
A weakness of many modern control methods is that they are based on forced directive control and make little use of the information situation model. This is conditioned by the fact that directive control needs no such model. Errors in directive control result in greater errors in the situation. Directive control is forced and mandatory, without regard to actual conditions.

Soft control makes use of conditions found in the actual situation with the controlled object. These conditions are converted to an information or a logical situation model. Only soft control makes use of the information situation as a control mechanism. Soft control is natural; it is permissible relative to actual conditions.

The issues with using soft control consist in the need for creating and applying an adequate situation model. It is the inability to create situation models that impedes the application of soft control. This article proposes a new information situation model. This model makes use of logical rules to allow or stop the traffic and describes a multitude of coordinated traffic variants having no contradictions with each other. The logical model version proposed in this work can be used in any kind of more complex situations with a similar topological structure. This is why, a mandatory condition for applying the given model is the topological model of a real traffic situation without which this logical model cannot be built, which imposes restrictions on its applicability.

\section{CONCLUSIONS}

The application of the information situation means a significantly weaker information burden on decision makers; it allows distinguishing only those factors of the environment that affect the controlled object. The application of the information situation allows spending much less time on analytical processing because it requires analyzing only the key, not all the parameters of the environment. Moreover, the information situation allows forming a system of control rules. This system can be used in computer-aided systems, intelligent transport systems, and in cyberphysical transport systems.

The application of the information situation allows considering the following peculiarity of the control process in the transport sector: the objects controlled therein are cargo streams, not individual objects. The information situation allows forming control models for individual objects and cargo streams, creating

conditions for situational control, and improving the efficiency of operating situation centers. Some of the technology solutions the situational control in the transport sector makes it possible to apply are distinguished below:

- applying GIScience techniques for controlling transportation infrastructure;

- applying global navigation satellite systems (GNSS) for traffic administration;

- applying digital space modeling in traffic administration;

- applying dynamic situation modeling;

- applying intelligent systems for traffic administration.

The lifting of traffic speed limits requires reducing time for decision making. Specialized situational control models help to solve these tasks. Increasing information volumes and the Big Data issue require using new approaches to information analysis. Information situation models result in a weaker information burden on both, man and computers. The classification of these models in partially provided in (Platze \& Quesel, 2008; Rozenberg, 2016), wheres this paper develops these ideas. This line of research requires further elaboration. The proposed logical traffic model relies on the logical information situation. The peculiarity of this approach is that the model is based on the topological model of a specific situation, which refers this technique to the domain of actual mathematics. 


\section{REFERENCES}

Abdelrahim, A., and Razdan, M. (2014). Are soft controls better than hard controls. Internal Auditor, Middle East.

Adamy, J., \& Flemming, A. (2004). Soft variable-structure controls: a survey. Automatica, 40(11), 18211844.

Alvarado, M. (1995). A posteriori knowledge: from ambiguous knowledge and undefined information to knowledge. In European Conference on Symbolic and Quantitative Approaches to Reasoning and Uncertaint ECSQARU 1995 (pp. 9-17). Springer: Berlin, Heidelberg.

Brouwer, L.E.J. (1908) .Unreliability of the Logical Principles [De onbetrouwbaarheid rer logische principes] Tijdschrift voor wijsbegeerte, 2.

Brouwer, L.E.J. (1907). Over de grondslagen der wiskunde. Amsterdam: Thesis.

Chtioui, T., \& Thiéry-Dubuisson, S. (2011). Hard and soft controls: mind the gap! International Journal of Business, 16(3), 289.

Ishikawa, H., Tsuchiya, A., \& Yamamoto, G. (2017). Management of mobile objects. US Patent No. 9805598.

Martin-Löf, P. (1982). Constructive mathematics and computer programming. Studies in Logic and the Foundations of Mathematics, 104, pp 153-175.

Mayer, J. H., Winter, R., \& Mohr, T. (2012). Situational management support systems. Business \& Information Systems Engineering, 4(6), 331-345.

Miyahira, T., \& Yamamoto, G. (2016). Management of mobile objects and service platform for mobile objects. US Patent No. 9460616.

Nemtanu, F. C., and Marinov, M. (2019). Digital Railway: Trends and Innovative Approaches. In V. Marinov (Ed.), Sustainable Rail Transport. Proceedings of RailNewcastle. Springer, Cham, pp. 257-268.

Pavlov, A. I. (2016). Spatial information situation [Prostranstvennaya informatsionnaya situatsiya]. Slavic Forum (Slavyanskiy forum), 4(14), 198-203.

Pietrzak, M. B. et al. (2014). The identification of spatial dependence in the analysis of regional economic development-join-count test application. In Proceedings of the 8th professor Aleksander Zelias international conference on modelling and forecasting of socio-economic phenomena. Foundation of the Cracow University of Economics: Cracow, pp. 135-144.

Platzer, A., Quesel, J. D. (2008). Logical verification and systematic parametric analysis in train control. International Workshop on Hybrid Systems: Computation and Control. Springer: Berlin, Heidelberg, pp. 646-9.

Rozenberg, I. N. (2016). Information Construction and Information Units in the Management of Transport Systems. European Journal of Technology and Design. 12(2), 54-62. doi: 10.13187/ejtd.2016.12.54 www.ejournal4.com.

Savinykh, V. P. and Tsvetkov, V. Ya. (2014). Geodata As a Systemic Information Resource. Herald of the Russian Academy of Sciences, 84(5), 365-8. doi: 10.1134/S1019331614050049.

Shchennikov, A. N. (2018). Logical Situations in Building Algorithms [Logicheskiye situatsii pri konstruirovanii algoritmov]. Slavic Forum, 3(21). 137-143.

Sigov, A.S. and Tsvetkov, V. Ya. (2015). Tacit Knowledge: Oppositional Logical Analysis and Typologization. Herald of the Russian Academy of Sciences, 85(5), 429-433. doi: 
10.1134/S1019331615040073.

Tsvetkov, V. Ya. (2012). Applying subsidiarity in information economy [Primeneniye printsipa subsidiarnosti v informatsionnoy ekonomike]. Financial Business, 6, 40-3.

Tsvetkov, V. Ya. (2012). Information Management of Mobile Object. European Journal of Economic Studies, 1(1), 40-4.

Tsvetkov, V. Ya. (2012). Information Situation and Information Position as a Management Tool. European researcher, 12-1(36), 2166- 2170.

Tsvetkov, V. Ya. (2015). Descriptive and prescriptive information models [Deskriptivnyye i preskriptivnyye informatsionnyye modeli]. Remote and Virtual Learning (Distantsionnoye $i$ virtual'noye obucheniye), 7(7), 48- 54.

\section{SEMBLANCE OF THE AUTHORS}

Stanislav A. Kudzh, Full Professor, Doctor of Engineering Sciences, chancellor at MIREA - Russian Technological University

Victor Ya. Tsvetkov, Full Professor, Doctor of Engineering Sciences, MIREA - Russian Technological University. 